研

究

\title{
$\mathrm{Bi}$ 系超電導体を用いた電磁波吸収体への応用
}

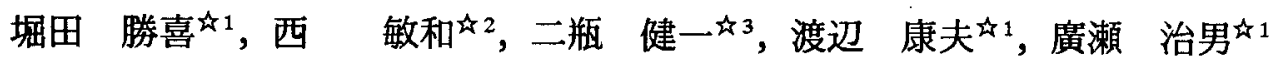 \\ 的日本工業大学, $\overline{3} 345-8501$ 埼玉県南埼玉郡宮代町学園台 4-1. \\ 42 日本工業大学大学院, $\overline{7}$ 345-8501 埼玉県南埼玉郡宮代町学園台 4-1. \\ ${ }^{3}$ 日本工業大学大学院, テ 345-8501 埼玉県南埼玉郡宮代町学園台 4-1 [(現) 富士通特機システム侏 ].
}

\section{Application of Bi-2223 Superconductor to Electromagnetic Wave Absober}

\author{
Katsuyoshi Hotta ${ }^{\uparrow 1}$, Toshikazu Nishi ${ }^{\star 2}$, Kenichi Nihei ${ }^{\star 3}$, Yasuo Watanabe ${ }^{\star 1}$ and Haruo Hirose ${ }^{\star 1}$ \\ ${ }^{1}$ Nippon Institute of Technology, 4-1 Gakuendai Miyasiro Minami-saitama-gun, Saitama 345-8501. \\ $\hbar^{2}$ Graduate School, Nippon Institute of Technology, 4-1 Gakuendai Miyasiro Minami-saitama-gun, Saitama 345-8501. \\ ${ }^{4}$ Graduate School, Nippon Institute of Technology, 4-1 Gakuendai Miyasiro Minami-saitama-gun, Saitama 345-8501
}

[Present Address: Tokki System Limited].

Received August 1, 2001

\section{SYNOPSIS}

We experimented on the reflective attenuation properties of $\mathrm{Bi} 2223$ superconductor against electromagnetic waves. Sample was prepared as a pellet $(32 \mathrm{~mm} \phi \times 2 \mathrm{~mm}$, or $32 \mathrm{~mm} \phi \times 5 \mathrm{~mm})$ which consists of the superconductor with the average particle size of $50 \mu \mathrm{m}$ or below and epoxy resin. The wt\% proportion of the superconductor and epoxy resin was changed to some extent.

The pellet was irradiated by the electromagnetic wave in the ranges from 10.0 to $11.0 \mathrm{GHz}(\mathrm{X}$ band) and from 20.0 to $26.0 \mathrm{GHz}$ ( $\mathrm{K}$ band) at $290 \mathrm{~K}$ and $77 \mathrm{~K}$ to measure its reflective intensity by using vector network analyzer.

The attenuation value defined in the experiment as a difference between reflective intensity of the sample and that of the same size copper plate gave the maximum attenuation of $60 \mathrm{~dB}$ at $10.5 \mathrm{GHz}$ for $\mathrm{X}$ band and that of $37 \mathrm{~dB}$ at $23.5 \mathrm{GHz}$ for $\mathrm{K}$ band.

The maximum attenuations of $52.7 \mathrm{~dB}$ at $10.7 \mathrm{GHz}$ and $63.3 \mathrm{~dB}$ at $25.2 \mathrm{GHz}$ were obtained for the average particle size of $170 \mu \mathrm{m}$ at $80 \mathrm{wt} \%$ content although no significant attenuations were observed for the particle size of $270 \mu \mathrm{m}$ at the same content.

Such attenuation properties will be understood in terms of a kind of percolation mechanism.

\section{KEY WORDS}

Superconductor, Bi system, Reflective attenuation, Electromagnetic waves Percolation

\section{1 緒言}

通信技術の発達が著しく，それに伴い電磁波障害などの諸 問題も生じており電磁波ノイス対策への関心も高まっている. 現在，電磁波吸収体として六方晶フェライト粉末を利用した 研究がなされている ${ }^{1)}$ が高温超電導体を用いた電磁波関連の 応用研究も注目を集めており，マイクロ波，ミリ波で性能の 良い平坦表面形状で薄型の電磁波吸収体が要求されている. このような背景のもとに，本報告では $\mathrm{Bi}$ 系高温酸化物超電導 体粉末を電磁波吸収体として応用することが可能か実験検討 を行った。

\section{2 実験方法}

平均粒径 $50 \mu \mathrm{m}$ で $\mathrm{Tc}$ が $104 \mathrm{~K}$ の Bi 系超電導体粉末をエポキ シ系樹脂に対する割合を $0 \mathrm{wt} \%$ 80 wt\%まで $10 \mathrm{wt} \%$ きざで 変化させて湿合し, $32 \mathrm{~mm} \phi \times 2 \mathrm{~mm}$ および $32 \mathrm{~mm} \phi \times 5 \mathrm{~mm}$ に成 形し試料とした。作製した試料を専用の治具に収め, ベクト ルネットワークアナライザを用い, 室温 $(290 \mathrm{~K})$ および液体窒 素温度 $(77 \mathrm{~K})$ で X帯 $(10 \mathrm{GHz} \sim 11 \mathrm{GHz}), \mathrm{K}$ 帯 $(20 \mathrm{GHz} \sim 26 \mathrm{GHz})$ の電磁波を試料に対し垂直に照射し反射強度を測定した。次 に，試料と同寸法の銅板からの反射強度を測定し，その差を 求めることにより電磁波の減哀量と定義し, 減衰量が $20 \mathrm{~dB}$ 以 上の帯域幅(20dB帯域)について比較を行った.また,この測 
定で結果が良かった割合のものについて平均粒径が $170 \mu \mathrm{m}$ と $270 \mu \mathrm{m}$ と粒径の遠う粉末で同寸法の試料を作製し，同様に電 磁波を照射し減衰量を測定した。

\section{3 実験結果並びに考轱}

$\mathrm{X}$ 帯 $(10 \mathrm{GHz} \sim 11 \mathrm{GHz})$ で試料厚さが $2 \mathrm{~mm}$ のときの超電尊体 含有量の変化に伴う減衰量の変化は, 超電導体の含有量の増

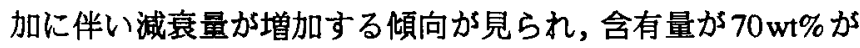
ピークで $80 w t \%$ では減衰量が著しく低下した。

Fig.1に超電導体粉末のエポキシ系樹脂に対する割合が $70 w t \%$

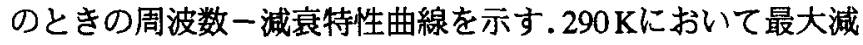
衰量が $47 \mathrm{~dB} て ゙, 20 \mathrm{~dB}$ 帯域が 10〜10.15 GHz の間の $0.15 \mathrm{GHz}$ となったが，77Kでは最大減哀量が $63.3 \mathrm{~dB}$ に達し， $20 \mathrm{~dB}$ 帯 域も $10 \sim 10.35 \mathrm{GHz}$ の間の $0.35 \mathrm{GHz}$ と大きくなった.

試料厚さが $5 \mathrm{~mm}$ のときの超電導体含有量の変化に伴う減衰 量の変化は，超電導体の含有量の增加に伴い減衰量が増加す る傾向が見られたが, 隇衰量が $20 \mathrm{~dB}$ を超えたのは含有量が $80 w t \%$ のきだけであった

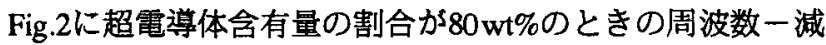

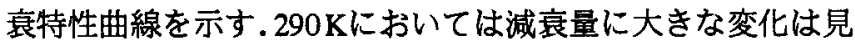

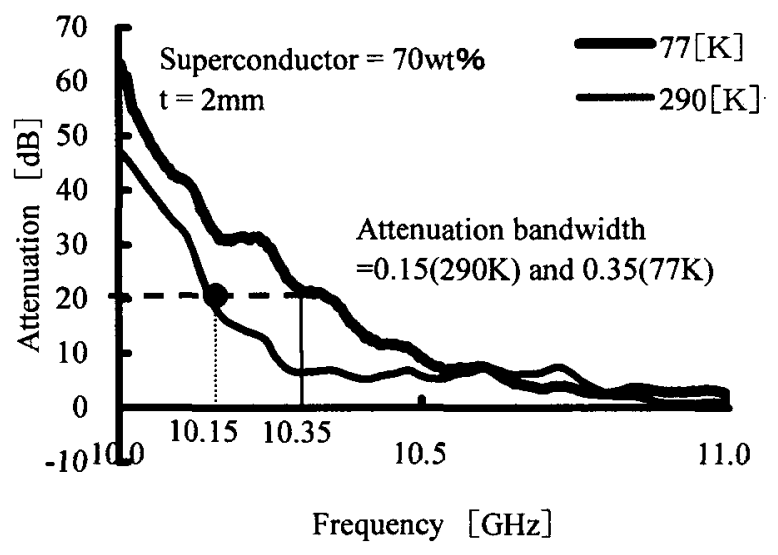

Fig.1 $\mathrm{X}$ band Attenuation ( $2 \mathrm{~mm}$ thickness sample $70 \mathrm{wt} \%$ superconductor).

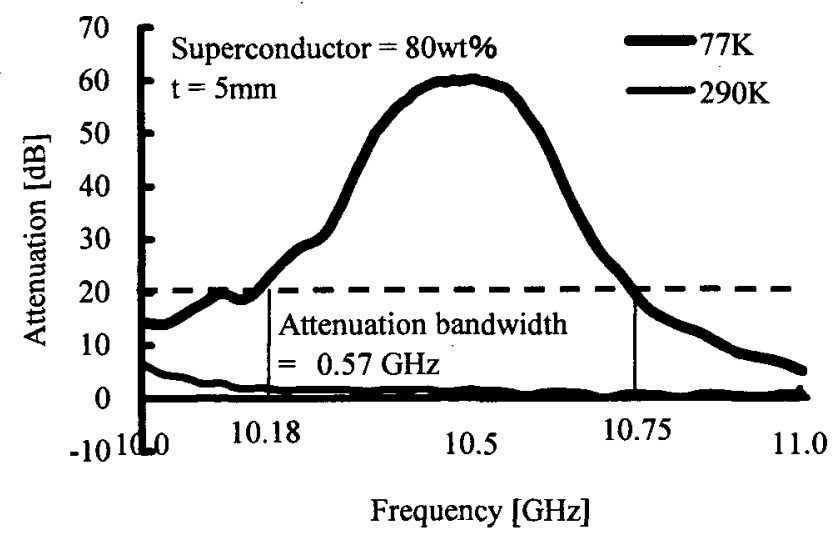

Fig.2 X Band Attenuation ( $5 \mathrm{~mm}$ thickness sample $80 \mathrm{wt} \%$ superconductor).

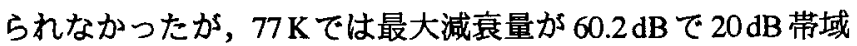
は $10.18 \sim 10.75 \mathrm{GHz}$ の間の $0.57 \mathrm{GHz}$ となった。

K帯(20 GHz $26 \mathrm{GHz})$ では, 試料厚さが $2 \mathrm{~mm}$ のとき超電 導体含有量の変化に伴う减衰量の変化は, 含有量が増加する と減衰量も若干增加する傾向が見られたが, 含有量 $60 \mathrm{wt} \%$ の ときがピークで全体で $20 \mathrm{~dB}$ を超えることはなかった.

Fig.3に超電導体粉末の割合が $60 \mathrm{wt} \%$ ときの周波数一減衰

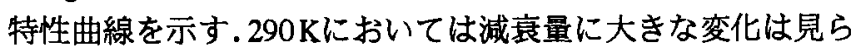
れず,77Kでも減衰量は若干增加する傾向が見られるものの， $20 \mathrm{~dB}$ を超えることはなかった。

試料厚さが $5 \mathrm{~mm}$ のときの超電導体含有量の変化に伴う減衰 量の変化は, 含有量が増加すると減衰量も増加する傾向が見 られ，含有量 $80 \mathrm{wt} \%$ でピークとなった。

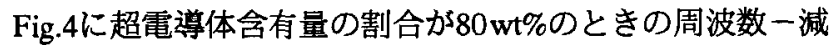

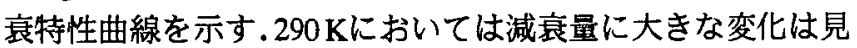

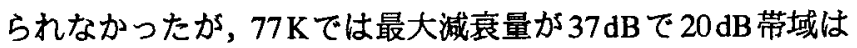
$22 \sim 23.55 \mathrm{GHz}$ の間の $1.55 \mathrm{GHz}$ となった.

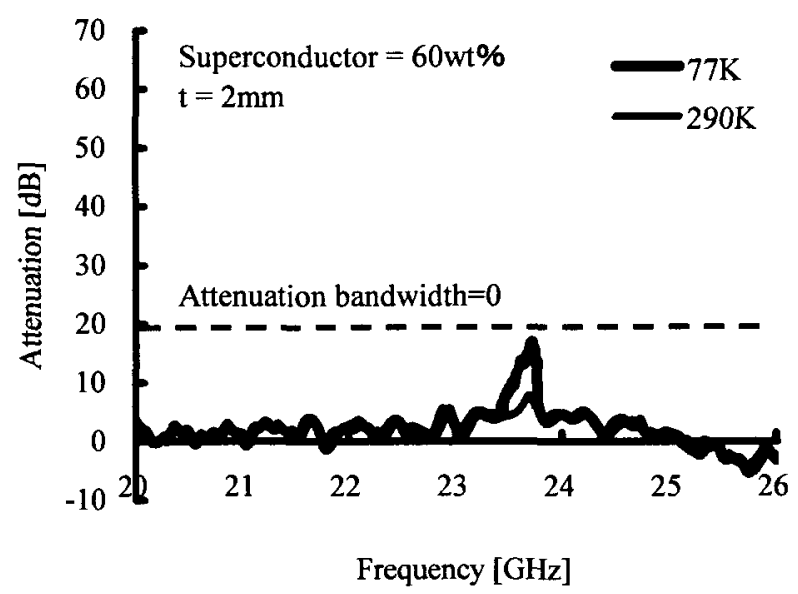

Fig.3 K Band Attenuation ( $2 \mathrm{~mm}$ thickness sample $60 \mathrm{wt} \%$ superconductor).

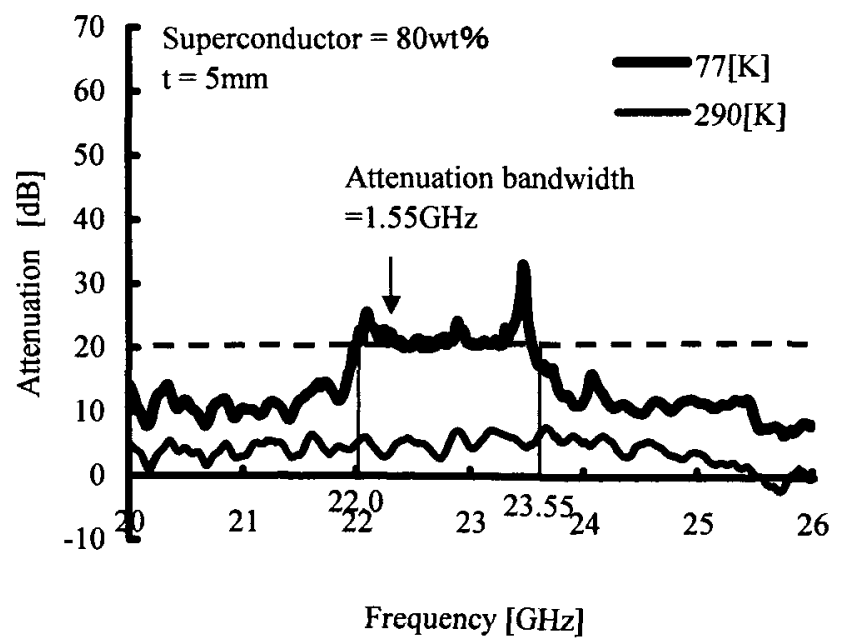

Fig.4 K Band Attenuation ( $5 \mathrm{~mm}$ thickness sample $80 \mathrm{wt} \%$ superconductor). 


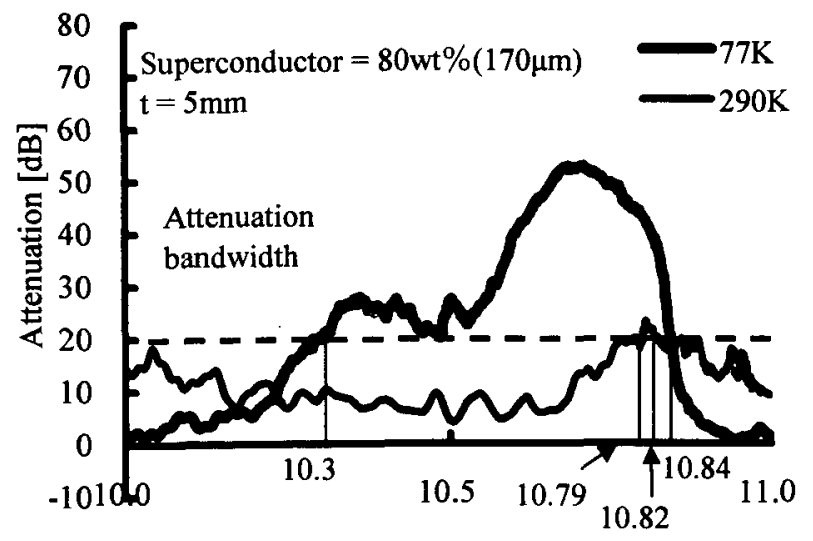

Frequency [GHz]

Fig.5 X Band Attenuation (5 mm thickness sample 80wt\% (170 $\mu \mathrm{m})$ superconductor).

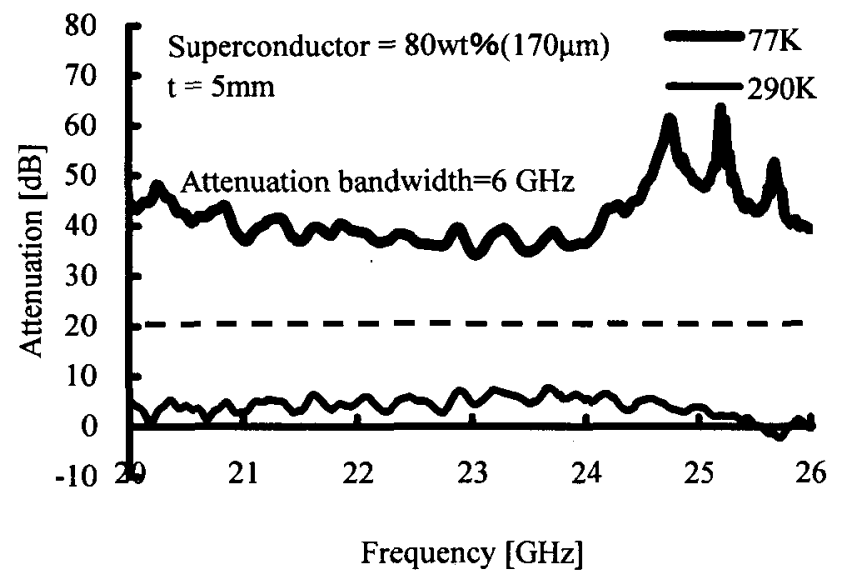

Fig.6 K Band Attenuation ( $5 \mathrm{~mm}$ thickness sample $80 \mathrm{wt} \%(170 \mu \mathrm{m})$ superconductor).

以上の結果より, 試料厚さ $5 \mathrm{~mm}$, 超電導体粉末の含有量は $80 \mathrm{wt} \%$ のきの結果が良好だったのでこの条件で平均粒径を $170 \mu \mathrm{m}$ と $270 \mu \mathrm{m}$ に大きくして測定を行った.

Fig.5に平均粒径 $170 \mu \mathrm{m}, \mathrm{X}$ 帯での周波数－減衰特性曲線を

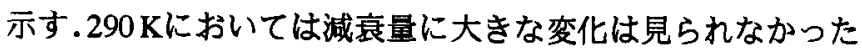
が, 77Kでは最大減衰量が52.7dBで 20dB帯域は 10.3 10.84GHz の間の $0.54 \mathrm{GHz}$ となった。

Fig.6に同じ試料で K 帯での周波数一減衰特性曲線を示す.

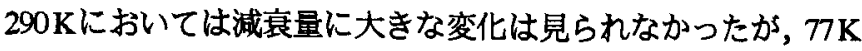
では最大減衰量が $63.3 \mathrm{~dB} て ゙ 20 \mathrm{~dB}$ 帯域は測定した周波数帯全 域,つまり $6 \mathrm{GHz}$ となった。

Fig.7に平均粒径 $270 \mu \mathrm{m}, \mathrm{X}$ 帯での周波数一減衰特性曲線を

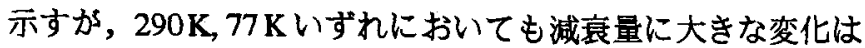
見られなかった。

Fig.8に Fig.7 と同じ試料で K 帯での周波数一減衰特性曲線 を示す. $290 \mathrm{~K}, 77 \mathrm{~K}$ いずれにおいても減衰量に大きな変化は 見られなかった。

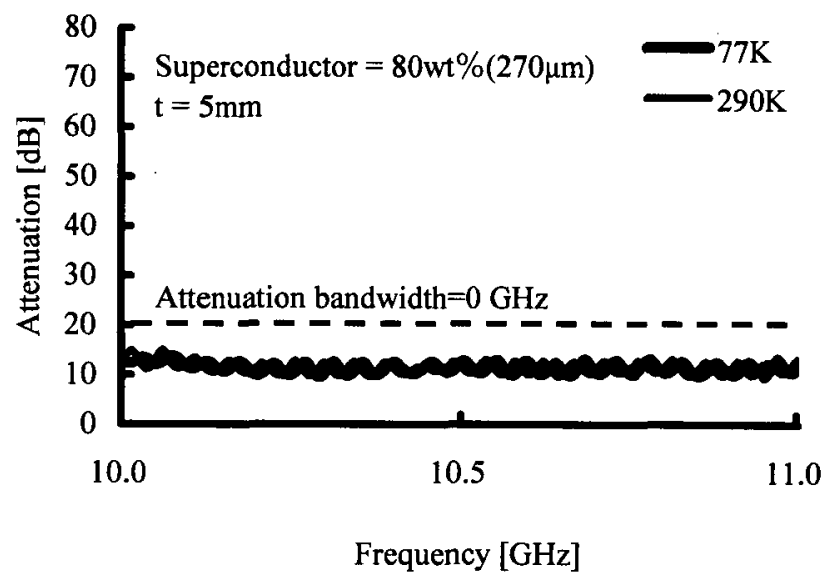

Fig.7 X Band Attenuation (5 mm thickness sample $80 \mathrm{wt} \%(270 \mu \mathrm{m})$ superconductor).

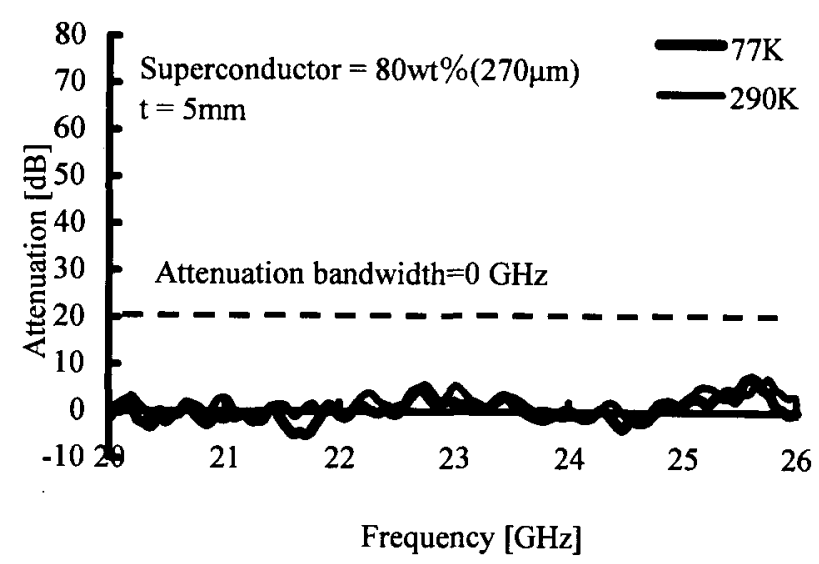

Fig.8 K Band Attenuation (5 mm thickness sample $80 \mathrm{wt} \%(270 \mu \mathrm{m})$ superconductor).

これらの事から，電磁波の減衰 ${ }^{2}$ には超電導体の粉末の含 有量 (分散の度合い) や粒度 (超電導体粉末の体積) が関与し ていることが明らかになった. それらを統一的に理解するに は，パーコレーションについての検討が試料の厚み，含有割 合，粒径および照射電磁波の波長の特性への影響の評価に有 効である可能性があると思われる. 従って試料の厚みに伴う 減衰量の変化については今後, パーコレーションの観点から 検討する必要があると考える.

\section{4 結 言}

本実験での条件のもとでは以下のことがわかった.

(1) 超電導体を用いて作製した試料が電磁波吸収体として応用 できる。

（2）超電導体の含有量は 70～80wt\% のとき，減衰量が大きく なる。

(3) 試料厚みは, $2 \mathrm{~mm} よ り 5 \mathrm{~mm}$ の方が良好な結果が得られる.

(4) 超電導体の粒径が $170 \mu \mathrm{m}$ のとき, 減衰量が最も大きくなる. 
(5) パーコレーションメカニスムを考虑する必要がある.

\section{文献}

1) S.Sugimoto, K.Okayama, S.Kondo, H.Ota, M.Kimura, Y.Yoshida, H.Nakamura, D.Book, T.Kagotani, M.Homma:
"Barium M-type Ferrite as an Microwave Absober in the $\mathrm{GHz}$ Range", Materials Transactions, JIM, (1998)1080-1083.

2) 花澤理広, 阿部康彦, 橋本修, 安岡義純: "抵抗皮膜を用い た700GHz帯用電波吸収体の実験的検討", 電子情報通信学 会論文誌, Vol. J84-B (2001)948-950. 